\title{
APORTACIONES A LOS RESPECTIVOS PROYECTOS DE LEY DE RÉGIMEN JURÍDICO DEL SECTOR PÚBLICO Y DEL PROCEDIMIENTO ADMINISTRATIVO COMÚN
}

\author{
José Luis Bermejo Latre \\ Profesor Titular de Derecho Administrativo. Universidad de Zaragoza \\ berlatre@unizar.es
}

\begin{abstract}
El texto que sigue reproduce buena parte de las sugerencias comunicadas el 23 de enero de 2015 al Ministerio de Hacienda y Administraciones Públicas acerca de los textos legales que, en fase de Anteproyecto, fueron expuestos a información pública en su día. El texto se limita a recoger mi visión de las cuestiones problemáticas sobre las que no se pronunciaron los participantes en la tercera sesión del Seminario sobre la Reforma del Estado tenida en el Instituto Nacional de Administración Pública el 12 de junio. Omito también deliberadamente las observaciones relativas a los aspectos relacionados con la Administración electrónica vertidas con ocasión de mi participación en la "Jornada de análisis de la propuesta de regulación de la Administración electrónica contenida en los anteproyectos de Ley de Procedimiento Administrativo y de Régimen Jurídico del Sector Público" organizada el 4 de mayo de 2015 por la Comisión de Expertos para la Reforma de la Administración Electrónica en el Centro de Estudios Políticos y Constitucionales. Las sugerencias y observaciones se alinean, formal y fundamentalmente, con los textos proyectados, ciñéndose a su estructura y contenidos y sin proponer (pero sí apuntar) novedades conceptuales más allá de las incorporadas por los autores de los textos.
\end{abstract}

\section{LA ESTRUCTURA DE LA LEGALIDAD ADMINISTRATIVA}

La reordenación del bloque de la legalidad administrativa en dos textos me parece cuestionable, máxime cuando los contenidos han sido repartidos entre ambos atendiendo únicamente a las dimensiones estática (relativa a la organización) y dinámica (relativa al procedimiento), que no son fácilmente disociables. En este sentido, cualquier modelo estructural es válido y defendible, y el elegido además cuenta con el precedente acreditado de los años cincuenta del siglo XX (LPA de 1958 y LRJAE de 1957).

Pero, en mi opinión, la ordenación más adecuada pasaría por la codificación de todos los aspectos regulatorios básicos comunes a todas las Administraciones públicas en un solo texto (una secuela de la Ley 30/1992, con los preceptos oportunos de la Ley 11/2007 entreverados o incrustados en un título específico), dejando aparte otro destinado a la unificación de los actuales textos de la Ley 50/1997 (Gobierno) y de la LOFAGE en todo lo que éstos regulen cuestiones privativas del aparato ejecutivo estatal. Semejante reparto de la regulación permitiría una mejor identificación de los contenidos y de su carácter básico o exclusivamente aplicable, así como la posibilidad de escalamiento del Código mediante la incorporación paulatina y depurada de otros bloques y/o contenidos nucleares del Derecho Administrativo (transparencia, contratación, empleo público, etc), todo ello en pos de la armonía, sincronía, univocidad y, en general, homogeneidad de la regulación.

\section{LA POTESTAD INSPECTORA}

La ley no contempla la regulación de las bases de la potestad inspectora en general, solo el valor de las actas de inspección (como la Ley 30/1992) y la entrada forzosa en domicilio (pero únicamente para la ejecución de actos administrativos). No se debería dejar pasar la ocasión para disponer una serie de normas, siquiera elementales, sobre el modo en que la inspección administrativa debe conducirse (aleatoria o programadamente, con o sin consentimiento del inspeccionado, con identificación del inspector, por funcionario o empleado público o privado habilitado por ley -o no-, etc.). En este apartado se podría dar pie ("incluyendo cuando ejercen potestades inspectoras y sancionadoras") a la regulación que eventualmente se introdujese en el capítulo correspondiente. 


\section{EL PROCEDIMIENTO DE ELABORACIÓN DE REGLAMENTOS}

Considerando que la elaboración de disposiciones de carácter general es una expresión de la actuación de las Administraciones públicas requerida, como cualquier otra, de unas reglas básicas comunes de procedimiento, parece que la norma legal más apropiada debería ser la reguladora del procedimiento, como sucedía en el texto originario del anteproyecto "LPAC" (ahora se mantiene la regulación en la Ley del gobierno, desacertadamente a mi juicio). La actual versión del "proyecto LPAC" se limita a regular algunos aspectos puntuales (publicidad normativa, planificación) y el trámite participativo, los cuales deberían contemplarse de manera unificada en una regulación procedimental completa. Por otra parte, la regulación de los principios de regulación y del procedimiento prelegislativo en general sería un contenido más propio del "Proyecto LRJSP", pero acaso con referencias a la eventual LPAC, Ilegado el caso.

\section{LOS INFORMES ADMINISTRATIVOS Y SU COLOCACIÓN EN EL PROCEDIMIENTO}

Se debería aprovechar la ocasión para regular de algún modo, siquiera elemental, las diferentes clases de informes (preceptivos, determinantes, habilitantes, vinculantes) porque no basta con la referencia a los preceptivos vs. facultativos. Los informes determinantes, habilitantes y, sobre todo, los vinculantes plantean problemas de dinámica procedimental que no están bien abordados con la regulación actual de la Ley 30/1992 ni tampoco con los textos propuestos. En particular, y por ejemplo, los efectos del silencio administrativo en la evacuación de informes vinculantes no puede ser equiparada sin más a los de los meramente preceptivos. También sucede que el art 22.1.d) parece disponer efectos estimatorios o positivos en caso de silencio en la emisión de informes preceptivos, pero ello puede desnaturalizar el sentido de los informes preceptivos que además gocen de carácter vinculante.

\section{LA PARTICIPACIÓN PÚBLICA}

Como resultado de la importación de todo el aparato teórico asociado al concepto de gobernanza, de la renovación del debate sobre la posición jurídica del administrado-colaborador con la Administración y del convencimiento de la importancia de la información como presupuesto de la participación, es creciente el interés por la cuestión de la presencia del público en la formación de la voluntad administrativa. Una vez trascendida la era de la regulación de la información pública (leyes de protección de datos, de transparencia y de reutilización de la información del sector público respectivamente), podría ser momento propicio para abordar la regulación de la participación pública, secuela natural de aquélla. Ha de notarse que el Derecho administrativo sectorial ya se ha hecho eco de estas nuevas preocupaciones y desarrollos surgidos en el entorno internacional y comunitario, particularmente en sede ambiental. Sin embargo, la normativa general sobre la materia sigue siendo insuficiente por arcaica, sectorialmente fragmentaria y superada por la realidad, en la medida en que se están ensayando al sin dar cabida a nuevas técnicas (presupuestos participativos, audiencias dramatizadas, conferencias y comités consultivos, consultas personalizadas a las partes afectadas, cuestionarios, encuestas, entrevistas y consultas populares, etc.).

Sin embargo, los textos propuestos renuncian siquiera a afinar y perfilar los mecanismos ya estatuidos en este ámbito, ampliando la regulación de los requisitos subjetivos, dinámicas participativas, exigencias formales y garantías de efectividad de los instrumentos y medios dedicados a la participación, etc. En este sentido, cabría ofrecer reglas más completas y sugestivas para la información pública del siguiente tenor:

“a) La información pública se efectuará en las unidades administrativas más cercanas a los interesados, además de en los diarios oficiales, sitios web administrativos, medios de comunicación y tablones de anuncios o edictos correspondientes.

b) Los anuncios de información pública indicarán claramente el expediente objeto de la misma y la duración del período, así como el lugar, horario y sitio web dispuestos para la consulta.

c) Durante la información pública:

Se podrá consultar toda la documentación relacionada con el expediente expuesto, en el lugar y horario dispuestos al efecto.

Se podrá consultar la documentación técnica relacionada con el expediente expuesto en la página web administrativa. 
Se podrán obtener copias de la documentación técnica relacionada con el expediente expuesto.

Se podrán presentar alegaciones, sugerencias, informes y todo tipo de documentos complementarios".

En general, convendría abordar con más ambición la regulación de la información y participación del público, contemplando, entre otros aspectos:

el deber de atender presencialmente las consultas de los particulares en horarios predeterminados (fijando unos mínimos temporales),

la provisión de medios de difusión complementarios a los diarios oficiales y las webs administrativas,

la presunción de veracidad de la información que se consigne en los documentos sometidos a información pública, precisando que se podrá actuar de acuerdo con los mismos y aludiendo, en su caso, a la responsabilidad patrimonial de las administraciones pública,

la necesidad de programación de las acciones de participación ciudadana con el fin de que su realización no resulte sistemática e irreflexiva,

la necesidad de protocolización de la sustanciación del trámite de información pública

un listado no exhaustivo de los instrumentos de información y participación, por ejemplo:

1. sesiones abiertas al público explicativas de las medidas administrativas a adoptar y de las posibles alternativas contempladas en la tramitación del expediente,

2. encuestas y consultas populares en caso de graves controversias ciudadanas sobre alguno de los aspectos de las medidas propuestas,

3. edición y/o distribución de material divulgativo o de resúmenes, al objeto de facilitar su difusión y comprensión, obligándose a emplear "términos y expresiones inteligibles para cualquier clase de administrado, de modo que los efectos de las medidas propuestas sean comprensibles sin dificultad".

g) la garantía de la evaluación del desarrollo del proceso de participación, mediante, por ejemplo, una "memoria informativa y justificativa, que deberá (...) describir el proceso de formulación y selección de alternativas para la adopción de decisiones, el análisis de las alegaciones, sugerencias y reclamaciones formuladas a título de participación ciudadana, y la justificación de las soluciones asumidas".

Llama la atención la ausencia de alguna norma relativa a la garantía de eficacia de la audiencia a los interesados, como sí la hay respecto de la información pública (en el sentido de que los concurrentes tienen derecho a obtener de la Administración una respuesta razonada).

En al apartado 83.1 recomiendo añadir una referencia a la posibilidad de considerar como de interés general de la resolución eventualmente adoptada, como causa de apertura del período de información pública, junto con la alusión a la naturaleza del procedimiento.

\section{EL CONTROL DE LA LEGALIDAD FINANCIERA Y CONTABLE}

Convendría aprovechar la ocasión para introducir una norma que reforzase las potestades revisoras (deberes, en realidad) de las Administraciones públicas frente a sus actos nulos cuando las irregularidades hayan sido puestas de relieve por organismos u órganos de control económico-financiero (Tribunal de Cuentas y homólogos autonómicos), cuyos actos de fiscalización no suelen gozar de ejecutividad frente a las actuaciones de las Admi- 
nistraciones auditadas en sectores puramente administrativos (contratación y empleo público, señaladamente). Dado que la gestión administrativa está viéndose paulatinamente condicionada por los instrumentos de control y auditoría a todos los niveles, parece oportuno que se puedan deducir consecuencias ejecutivas para la mejora de la Administración de las prácticas de estos controles. Se impone un espacio para la regulación —siquiera superficial, pero en todo caso sintética- de esta cuestión en la normativa básica de régimen jurídico de las Administraciones Públicas y/o del procedimiento administrativo común.

\section{LA POTESTAD SANCIONADORA}

El "Proyecto LPCA" no regula con carácter general los "mecanismos de clemencia", solo en sus art. 62.3 b) (premiando la delación, figura que debería ser regulada con cuidado y, en todo caso, distinguida de la denuncia) y 85.3 (obligando a la Administración a reducir las sanciones en una proporción mínima del $20 \%$, condicionada al no ejercicio de acciones contra la sanción). Al menos una horquilla de mínimos y máximos sobre el porcentaje de la reducción previsto en el párrafo final del art. 85.3 se debería establecer en una norma con rango legal, so riesgo de lesionar los principios de legalidad y tipicidad de las sanciones contemplados a la luz de los principios de igualdad y de seguridad jurídica. En general, estos mecanismos de clemencia requieren, a mi juicio, de una reflexión más intensa en cuanto a su extensión y efectos.

La prohibición non bis in idem debería extenderse también a las infracciones sancionadas por órganos y/o organismos de la UE, no bastando la previsión de minoración de la sanción nacional recogida en el art. 31.2 del "Proyecto LRJSP": la Administración de la Unión Europea es también Administración.

Se debería hacer alguna referencia a la necesaria preservación de la identidad del denunciante, en sintonía con la jurisprudencia constitucional al respecto.

La imposición de sanciones debería reservarse al momento en que se haya tramitado "y resuelto (acaso también notificado)" el procedimiento.

Es preferible -y más congruente con la jurisprudencia al respecto- emplear en el art. 90.3 la locución "firme en vía administrativa" que "con carácter ejecutivo" al dotar de carácter obstativo a los procedimientos sancionadores en curso.

La ejecutividad de la resolución sancionadora (art. 90.3 del "Proyecto LPACA) debería referirse al momento de la firmeza de ésta en vía administrativa, empleándose el término legal usual en lugar de su explicación ("que no quepa contra ella ningún recurso...").

\section{ASPECTOS PUNTUALES}

1. La regla de suplencia debería aplicarse no solo a los titulares de órganos administrativos sino también a sus miembros en general, para dar cobertura a este fenómeno cuando sucede en órganos colegiados.

2. Si se dispusiera la obligatoriedad de grabación de las sesiones de órganos colegiados, las actas podrían reducirse a la expresión de los acuerdos adoptados, sobrando toda referencia a "los puntos principales de las deliberaciones". Con ello se simplificaría la labor de secretariado, siendo las actas videográficas o sonoras siempre accesibles en virtud de la legislación de transparencia.

3. Los interesados referidos en el apartado b) del art. 4.1 del "Proyecto LPACA" podrían merecer tal consideración incluso en el caso de que ostenten intereses legítimos, y no solo derechos. La actual redacción del art. 8 ("nuevos interesados") se expresa en términos extensivos y parece aconsejable una conexión lógica entre ambos preceptos en uno o en otro sentido, siendo preferible el extensivo (o proactivo).

4. La alusión del art. 14.2.b) del "Proyecto LPACA" a las entidades sin personalidad jurídica es antitética: si son entidades, gozan de ella. Si no gozan de ella, son meras agrupaciones o plataformas, siendo estos términos (mejor el primero) más aconsejables.

5. Se echa en falta una norma coercitiva que refuerce la obligación recogida en el art. 18.2 del "Proyecto LPACA".

6. Convendría unificar la redacción de los apartados 3 y 4 del art. 30 del "Proyecto LPACA" en aras de la claridad, en el siguiente sentido:

“3. Los plazos expresados en días, meses o años se contarán a partir del día siguiente a aquel en que tenga lugar la notificación o publicación del acto de que se trate, o desde el siguiente a aquel en que se produzca la estimación o la desestimación por silencio administrativo. 
4. Si el plazo se fija en meses o años, éste concluirá el mismo día en que se produjo la notificación, publicación o silencio administrativo en el mes o el año de vencimiento. Si en el mes de vencimiento no hubiera día equivalente a aquel en que comienza el cómputo, se entenderá que el plazo expira el último día del mes".

7. Se debería traer al art. 48.1 del "Proyecto LPACA" la definición de desviación de poder contenida en el art. 70.2 de la Ley de la Jurisdicción Contencioso-Administrativa, y/o vincular este precepto de algún modo con el 34.2 del citado proyecto.

8. Convendría articular los arts. 38 y 98 del "Proyecto LPACA", acaso llevando el contenido del 38 al propio 98. En general, la denominación y tratamiento de la ejecutividad es deficiente, porque no es posible distinguir este concepto (ejecutividad) del aludido por la rúbrica (ejecutoriedad) a pesar de emplearse términos diferentes. De hecho, y a mayor abundamiento, la previsión del apartado d) del artículo hace referencia a una cuestión de eficacia, extraña por lo tanto al fenómeno de la ejecutividad (es un presupuesto de ésta, en realidad).

9. Convendría ceñir la referencia del art. 46 del "Proyecto LPACA" a la afección de la notificación edictal o publicación a los derechos o intereses legítimos "relativos a la intimidad/privacidad".

10. El art. 68.1 del "Proyecto LPACA" debería ceñir la posibilidad de requerir la subsanación no solo a los requisitos previstos por el art. 66 sino además, más precisamente, a los que resulten esenciales para la tramitación del procedimiento. El resto de requisitos serían, pues, comprobables a la terminación del procedimiento, determinando una ratificación de la resolución adoptada o una modificación del mismo. En realidad, el entero tratamiento de la ordenación del procedimiento (exigencia documental, comprobación de requisitos, subsanación, etc.) adolece de un carácter excesivamente conservador, pudiendo haberse avanzado hacia fórmulas de autorregulación en la acreditación de requisitos y descarga administrativa.

11. La acumulación de procedimientos debería ser obligatoria, en aras de la eficiencia y celeridad administrativas y de la igualdad y seguridad jurídicas.

12. Se atisba en el art. 88.5 del "Proyecto LPACA" una regulación de la inadmisión muy puntual, parca y en todo caso instrumental. Se debería aprovechar la ocasión para introducir un trámite de inadmisión con carácter general, aplicable a todo procedimiento administrativo, con referencia a las causas de inadmisión (solicitudes reiterativas), el plazo y los efectos impugnatorios, etc.

13. De la toma "en cuenta por el órgano competente al redactar la correspondiente propuesta de resolución" de las alegaciones y documentos prescrita por el art. 76.1, segundo párrafo, del "Proyecto LPACA" debería quedar constancia documental en el expediente, acaso con la siguiente fórmula: “Unos y otros serán tenidos en cuenta por el órgano competente al redactar la correspondiente propuesta de resolución, de lo cual quedará constancia documental en el expediente".

14. La admisión de la aceptación de informes o dictámenes como remedo de la motivación de una resolución debería condicionarse a que en ésta se incorporase, siquiera en extracto, los argumentos o motivaciones de los informes o dictámenes aceptados.

15. La revocación de actos administrativos y la rectificación de errores merecen sendos artículos diferenciados, pues las figuras en ellos regulados son naturalmente distintas, y distintos sus efectos (eventualmente indemnizatorios en el caso del error).

16. El art. 30 del "Proyecto LRJSP” no regula la responsabilidad disciplinaria del responsable de la tramitación de un expediente en el que operen la prescripción y/o caducidad, a diferencia de cuanto sucede en el art. 20 del "Proyecto LPACA", cuyo contenido se podría replicar a estos efectos.

17. La condición establecida en el último inciso del apartado 5 del art. 32 del "Proyecto LRJSP" podría contravenir la doctrina sentada por la STJUE de 26 de enero de 2010 (Asunto C-118/08. Transportes Urbanos), que establece la innecesariedad de la reclamación previa, anterior a la Sentencia del TJUE que declare el incumplimiento estatal del Derecho de la UE como presupuesto para la reclamación de responsabilidad patrimonial del Estado legislador.

18. Las previsiones contenidas en el párrafo primero del art. 131 del "Proyecto LPAC", así como en la nueva redacción propuesta para el art. 23 de la Ley del Gobierno por parte de la Disp. Final $12^{a}$ del "Proyecto LRJSP" requieren, a mi juicio, una más depurada articulación con el Código civil, que no se reduzca a la salvedad o reconocimiento de la vigencia de éste. 